\title{
LA CARTOGRAFÍA Y LA RACIONALIDAD AMBIENTAL: EN BÚSQUEDA DE LA SUPERACIÓN DE LA RACIONALIDAD INSTRUMENTAL
}

\author{
A CARTOGRAFIA E A RACIONALIDADE AMBIENTAL: EM BUSCA DA \\ SUPERAÇÃO DA RACIONALIDADE INSTRUMENTAL
}

\author{
CARTOGRAPHY AND ENVIRONMENTAL RATIONALITY: IN SEARCH OF \\ OVERCOMING THE INSTRUMENTAL RATIONALITY
}

Celeste Dias Amorim

Faculdade Pitágoras - Brasil

Luiz Artur dos Santos Cestari

Universidade Estadual do Sudoeste da Bahia - Brasil

\begin{abstract}
Resumen: Este artículo presenta el movimiento contemporáneo de la cartografía y la racionalidad ambiental como medio de superar el paradigma moderno que promueve la instrumentalización de la ciencia. En este caso, el enfoque explorado se encuentra en la frontera entre el movimiento de la modernidad y el de la contemporaneidad en lo que concierne al concepto de hacer ciencia. De esa forma, el camino que seguiremos en este texto hará un recorrido entre estos dos movimientos. Se partirá del diagnóstico de la crisis de la modernidad presentado por Boaventura de Souza Santos y la influencia del mismo en el debate sobre las cuestiones ambientales de manera fiel a como lo hizo en este ámbito Enrique Leff, por ejemplo, y enseguida, basado en los estudios de otros autores como Bruno Latour que buscan presentar un modo de producir conocimiento que se presenta como cartográfico. En este sentido, promueve la aproximación del discurso de la racionalidad ambiental al discurso de la cartografía, que en este momento podrá ayudar a superar la racionalidad instrumental.
\end{abstract}

Palabras clave: Modernidad; Teoría del Actor-Red; Rizoma.

\begin{abstract}
This article presents the contemporary movement of environmental rationality and cartography as a means of overcoming the modern paradigm that promoted the instrumentalisation of science. In this case, the exploited approach lies on the border between the movement of modernity and contemporaneity regarding the conception of doing science. Thus, the topics that we will cover in this paper are related to these two movements. According to the diagnosis of the crisis of modernity presented by Boaventura de Souza Santos and the influence of the debate on environmental issues as introduced in this area by Enrique Leff, for example, and then, based on the authors of studies as Bruno Latour we seek to present a way of producing knowledge that is presented as cartographic. For that matter, promoting the approach of the discourse of environmental rationality to the discourse of cartography at this point can help overcoming instrumental rationality.
\end{abstract}

Keywords: Modernity; Actor-Network Theory; Rhizome. 
Resumo: Este artigo apresenta o movimento contemporâneo da racionalidade ambiental e da cartografia como meio de superação do paradigma moderno que promoveu a instrumentalização da ciência. Neste caso, a abordagem explorada encontra-se na fronteira entre o movimento da modernidade e da contemporaneidade no que diz respeito à concepção do fazer ciência. Assim, o caminho que percorreremos neste texto passa por estes dois movimentos. Sendo que parte-se do diagnóstico da crise da modernidade apresentado por Boaventura de Souza Santos e da influência deste no debate sobre as questões ambientais tal como introduzidas neste domínio por Enrique Leff, por exemplo, e, em seguida, baseado nos estudos de outros autores como Bruno Latour busca apresentar um modo de produzir conhecimento que se apresenta como cartográfico. Neste sentido, promover a aproximação do discurso da racionalidade ambiental ao discurso da cartografia, neste momento poderá contribuir para a superação da racionalidade instrumental.

Palavras-chave: Modernidade; Teoria de Ator-Rede; Rizoma.

\section{Tejiendo las consideraciones iniciales}

Actualmente la preocupación por el lugar donde vivimos ha promovido cambios en el comportamiento y una mayor disposición al diálogo dando lugar a discusiones sobre las cuestiones ambientales. Esto se debe al deseo generado por la emergencia de un paradigma impulsado por una nueva racionalidad sobre el ambiente.

Según Santos $(1995,2002,2008)$ la modernidad se rige por la racionalidad universal que establece la visión de un mundo fragmentado y dicotómico. Con la crisis de la razón, la racionalidad universal no pudo sostener la verdad absoluta. Desde la década de 1960 debido a las demandas sociales (trabajo, género, medio ambiente, niño / adolescente, orientación sexual etc.) con la intención de contribuir en los procesos de formación de las conductas individuales y colectivas en la dirección de las relaciones sociales y el aumento de la participación ciudadana en la construcción de una sociedad más justa, hubo una fragmentación de la racionalidad universal, entonces esto no se entiende como una verdad única, sino varias verdades, como si fueran mini-racionalidades, de tal forma que con el discurso de una sociedad ecológicamente sostenible, también aparece, una nueva racionalidad con enfoque ambiental. Como lo observa Leff $(2009$, p. 18)

La racionalidad de la modernidad pretende poner a prueba la realidad, colocándola fuera del mundo que percibimos con los sentidos y de un saber engendrado al surgir del mundo de la vida. El saber ambiental incluye el conocimiento racional y el conocimiento sensible [...].

[...] El saber ambiental hace renacer el pensamiento utópico y las ganas de libertad en una nueva racionalidad en la cual se funden el rigor de la razón y los excesos del deseo, la ética y el conocimiento, el pensamiento racional y la sensualidad de la vida. La racionalidad ambiental deja paso a una reerotización del mundo, transgrediendo el orden establecido, el cual impone una prohibición de ser. 
En este enfoque Leff nos lleva a pensar sobre el movimiento del conocimiento realizado por el ser humano en busca de cambios que llevaron a algunas etapas importantes en la historia humana, por ejemplo, la modernidad. Esto nos hace reflexionar nuestra investigación sobre: ¿De cuál y de qué forma buscaremos este conocimiento? ¿El presente sería el tiempo que busca, o el pasado o el futuro que vendrá? ¿Estamos atrapados o tratando de vivir un pasado? ¿Qué nos lleva a pensar que vivimos en un futuro eterno?

Cierto, en el presente es necesario ir y venir, reportarse al pasado y pensar en el futuro, sin embargo, dice Santos $(2010,2011)$ necesitamos vivir el presente, pero en sus entre-lugares como lo señala Bhabha (2013), donde el sujeto de frontera puede realinear el espacio y el tiempo, y hacer su intervención aquí y ahora, o sea, en el presente.

Corroborando este enfoque sobre el pasado, el presente y el futuro, Latour (1994, p. 74) nos dice que "seguramente tenemos un futuro y un pasado, pero el futuro se asemeja a un círculo que se expande en todas las direcciones, y el pasado no se encuentra ultrapasado, sino volviendo, repitiendo, envolviendo, protegido, recombinado, reinterpretado y recompuesto".

Reflexionando sobre lo que expone Boaventura de Souza Santos y Enrique Leff, vemos que en presente vivimos una crisis civilizatoria que se desencadenó debido a la falencia del ambicioso proyecto del paradigma moderno dominante que dio lugar a un desencanto mundial, pero también trae consigo una emergencia ${ }^{1}$ un movimiento en búsqueda de una nueva ética, de una nueva relación, una nueva forma de saber, de nuevos sentidos... de una nueva racionalidad como una manera de superar el instrumentalismo de la razón que promueve el individualismo (LEFF, 2009; SANTOS, 2008, 2010, 2011), también en la perspectiva de Agamben vivimos un movimiento del tiempo del ahora e del todavía no, o sea, del límite del tiempo que pasó y del que va a pasar. De esta forma, en esta comprensión del tiempo basamos nuestra noción de lo que entendemos por contemporáneo, en que lo "Contemporáneo es aquél que recibe en la cara el aliento de las tinieblas que provienen de su tiempo" (AGAMBEN, 2009, p. 64), en que el presente

[...] tiene rotas las vértebras. Nuestro tiempo, el presente, no es, de hecho, sólo el más distante: en ningún caso puede alcanzarnos. Su espalda está rota, y nosotros nos mantenemos exactamente en el punto de la fractura. Por eso somos, a pesar de todo, contemporáneos a ese tiempo. Entiendan bien que el compromiso del que se trata en el mundo contemporáneo no tiene un lugar simplemente en el tiempo cronológico: es, en el tiempo cronológico, algo que urge dentro de éste y que lo transforma. Y esta urgencia es la intemporalidad, el anacronismo que nos permite capturar nuestro tiempo en la forma de un

\footnotetext{
1 La emergencia aquí se observa a través de la Sociología de las Emergencias de Santos (2010, 2011), que permite abandonar la idea de un futuro sin límite para un concreto, basado en las emergencias de las realidades llenas de alternativas y posibilidades que no existían antes y, a partir de ahí, se va construyendo el futuro, en una superación de la razón prolíptica.
} 
'muy temprano' que también es un 'muy tarde', un 'ahora' que también es un 'todavía no'. Y, de la misma forma, reconocer en las tinieblas del presente la luz que, sin nunca podernos alcanzar, está perennemente viajando hacia nosotros (AGAMBEN, 2009, p. 65-66).

No se trata aquí de hacer lecturas diferentes del tiempo, sino mostrar la manera como las percepciones se relacionan, se complementan y expresan una comprensión del movimiento de frontera del espacio y del tiempo entre presente, pasado y futuro. En que, mediante esta comprensión podamos abordar el movimiento del conocimiento, el cual nos orientará sobre la concepción de lo moderno y lo contemporáneo.

Ante lo expuesto, percibimos que para entender estos movimientos debemos hacer el camino de las concepciones que respaldan estos movimientos, para tanto pasaremos inicialmente a presentar el concepto de modernidad y posteriormente a mostrar algunos movimientos que traen una perspectiva que visan la superación del paradigma moderno, a estos movimientos algunos autores los llaman post-moderno, aunque Santos (2002, 2008, 2010, 2011), defienda que estamos caminando para esta fase, pues aún nos encontramos en una fase transición, por eso y por no tratarse aquí de un espacio continuo y de un tiempo cronológico, no será adoptado el término movimiento post-moderno sino el de movimiento contemporáneo, aún más, porque, este último es un término que se sitúa un tiempo en proceso, pero con expectativa de rupturas del saber que trae un ideal de una única verdad.

\section{Modernidad: paradigma sócio cultural dominante}

La crisis del modelo civilizatorio en que vivimos, en que las certezas de la ciencia moderna que fomentó el proyecto ambicioso de la dominación y del control en búsqueda de más y más poder (SANTOS, 2008), que "decididamente, ellos son, fueron, casi fueron, se creyeron invencibles" (LATOUR, 1994, p. 44), así por creer que pisaban en terreno firme, asumieron según Silva (2015, p. 12), la hybris (desmedida) como virtud, como duras baldosas, ahora se ve que andaban sobre caminos de barro, frágil y relleno de dudas. En este caso,

Los modernos no sólo exageraron la universalización de sus ciencias - al arrancar la fina red de prácticas, instrumentos e instituciones que cubría el camino que llevaba de las contingencias a las necesidades - sino también, simétricamente, exageraron el tamaño y la duración de sus sociedades. Creyeron que eran revolucionarios, porque inventaron la universalidad de las ciencias, arrancadas para siempre de los particularismos locales [...] (LATOUR, 1994, p. 118).

El avance de la ciencia moderna tiene como marco, el Renacimiento Científico, que fue un movimiento caracterizado por el racionalismo y el empirismo. En este movimiento, surgió 
el método de los principios cartesianos. La ciencia se divide, dando origen a otras ciencias como la Física, la Biología, la Química, la Economía y la Sociología. A partir de entonces "la ciencia se hacía cada vez más específica y operacional, creando para sí un mundo propio, pasible de ser explicado, experimentable y dominable" (FRANCELIN, 2004, p. 28).

El método científico moderno o método cartesiano de René Descartes (Discurso del Método) implantó otra forma de pensar, lo que llevó a la ruptura definitiva con el dogmatismo religioso y al marco inicial de la edad moderna, influyendo en los conceptos y valores del ser humano hacia una nueva manera de ver el mundo, de pensar el ser humano, la sociedad, la naturaleza, de pensar sobre sí mismo (ANDRADE, 2008; COSTA, 2015).

El mayor representante del racionalismo, René Descartes, al proponer la matemática como modelo de la ciencia perfecta, inauguró, decisivamente, el pensamiento moderno, indicando el uso disciplinado de la razón como camino hacia el conocimiento verdadero y definitivo de la realidad. Propuso principios para esa nueva forma de producción de saberes, caracterizada por una serie de operaciones de descomposición de la cosa a conocer y su reducción a las partes más simples. Ese nuevo método científico sustituyó la fe por la razón, la filosofía por la ciencia (PIMENTEL, 2015, p. 109).

Así, el racionalismo proveniente del método cartesiano excluyendo todas las consideraciones acerca del valor, de la perfección, del sentido y del fin, crea divisiones, separaciones, distinción entre hombre-sujeto, naturaleza-objeto y hombre-naturaleza. El hombre, impregnado del pensamiento moderno, es llevado a creer que podrá controlar todas las formas de conocimiento, estableciendo una racionalidad universal con una visión fragmentada y dicotómica del mundo (ANDRADE, 2008, MORIN, 2004, 2005).

Del mismo modo, Latour (1994, p. 15; 45) explica que por medio del “[...] adjetivo moderno, señalamos un nuevo régimen, una aceleración, una ruptura, una revolución del tiempo [...]". Esto por el ideal de una sociedad libre, "pero el precio a pagar por esta libertad sería que los modernos permanecieran incapaces de pensar sobre sí mismos”.

Según Pimentel (2015, p. 109) "pocos fueron los momentos de la humanidad en que se vivenció una tensión tan profunda. Ese contexto representó un cambio conceptual en la visión del mundo".

Históricamente se puede identificar en el proyecto de modernidad una importancia causada por las transformaciones desencadenadas por las grandes revoluciones religiosa y científica resultantes del movimiento iluminista, como la Revolución Francesa, la Revolución Industrial y la Revolución Americana para el despegue del paradigma moderno. De esa manera, al establecer un formalismo y un objetivismo estrechos, la "razón iluminista, se vació de su 
sentido ético y político, perdiendo su carácter humano y su valor universal” (COSTA, 2015, p. 161).

Otro estudio decisivo en la consolidación del universalismo de la ciencia moderna fue en cuanto a las leyes de la mecánica establecidas por Isaac Newton que reforzaron el paradigma sociocultural dominante, instituyendo que todos los sucesos de la naturaleza son gobernados por estas leyes, por lo tanto, a partir de ahí se crean las leyes universales y regentes del mundo. Para Grün (2005, p. 40), “el programa establecido por la mecánica newtoniana establece una nueva visión de mundo. El mecanicismo pasa a ser la única forma legítima de hacer ciencia. La mecánica clásica se convierte en la visión hegemónica de la realidad".

Como residuo de la tecnociencia produjo la racionalidad instrumental o la razón indolente (SANTOS, 2002) que aporta el saber de forma reducida a la técnica, pues según Latour (1994, p. 113) los modernos “confundieron productos con procesos. Creyeron [...]; que la producción de una ciencia universal dependía de sabios universalistas; que la producción de técnica eficaz acarreaba la eficacia de los ingenieros [...]”. Así, para Matos la razón pasa a ser

[...] instrumental, formal y despersonalizadora, para la cual importan sólo la eficiencia y el éxito, según la creencia en un nuevo control humano del universo, en el cual el individuo es capaz de hacer siempre más y de administrar enteramente la vida, el cuerpo y, así, dominar riesgos. (MATOS, 2010, p. 157).

Esta razón instrumental privilegia "la eficacia de los procedimientos, el poder de la manipulación y la inmediatez de los resultados, acabando por confundir el saber con el poder o aún reducir aquél a éste", produciendo "una imagen técnica del mundo, que se refleja en la posición del sujeto", en que el "perfil instrumental, que expresa y, a la vez, es expresión de una correlación, anuladora de diferencias, entre el conocimiento y el poder" (COSTA, 2015, p. 160161).

El avance de la racionalidad técnico-instrumental se hace paradójicamente por el déficit de la emancipación humana, pues la razón indolente contrae y disminuye el presente cuando deja de fuera la realidad y las experiencias (razón metonímica) y expande infinitamente el futuro (razón prolíptica), con eso se produce una ausencia de la realidad (SANTOS, 2002, 2010, 2011).

A esta ausencia, en que su producción es el resultado de cinco modos de producción de mono culturas, Santos $(2010,2011)$ propone la terminología "Sociología de las Ausencias", donde intenta mostrar que hay realidades y experiencias que se vuelven invisibles a la realidad hegemónica del mundo que provoca la sustracción del presente (Figura 1).

Así, según Silva (2015) la ciencia y la técnica se convierten en productos de la cultura humana, constituyendo junto como otros saberes uno de los aspectos de la realidad del mundo, 
pues ese "modo de civilización, que se estructuró a partir de la sociedad occidental y, extendiéndose por todo el planeta, quiere ser [o imponerse como] 'el' modelo de civilización" (COSTA, 2015, p. 159).

Figura 1 - Modos de producción de monoculturas

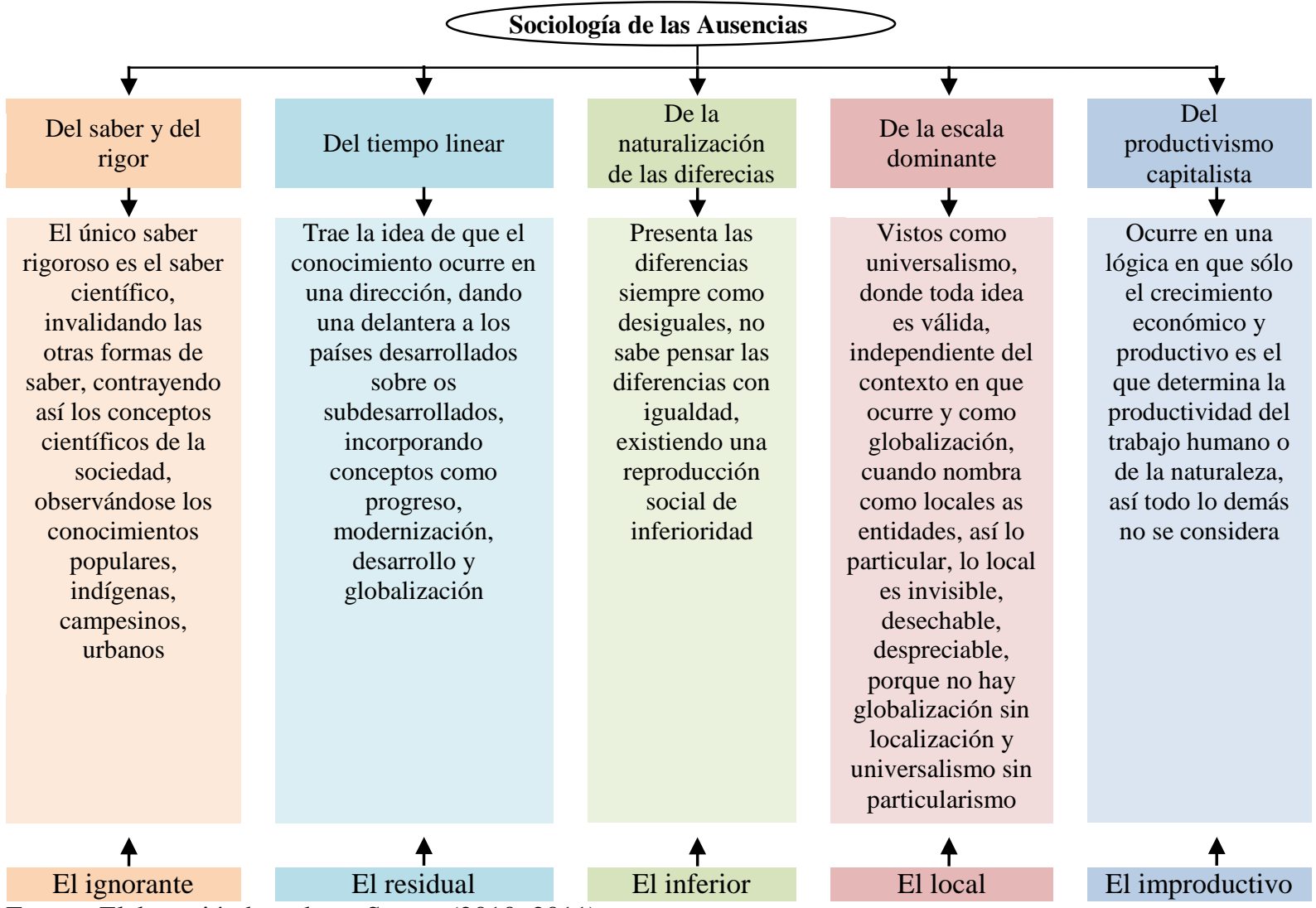

Este modelo de civilización Latour (1994) lo entendió como un delirio moderno muy difícil de calmar y Santos $(2008,2010$, 2011) lo denominó paradigma sociocultural dominante que se constituyó de "un proyecto ambicioso y revolucionario", que contempla muchas promesas difíciles de ser cumplidas y su exceso ocurre en el propio objetivo, que se une en el pilar de la regulación y en el pilar de la emancipación.

Según Santos (2008), el proyecto ambicioso de la modernidad posee dos formas de conocimiento: el pilar de la regulación representado por el Estado, la comunidad y el mercado y el pilar de la emancipación representado por la racionalidad, estético-expresiva, cognitivoinstrumental y práctico-moral del derecho. El autor señala que para cada pilar hay dos puntos extremos: el conocimiento y la ignorancia, en que el conocimiento es representado en el primer pilar por el orden y en el segundo por la solidaridad. La ignorancia, por el caos y por el colonialismo, respectivamente. En este caso, Santos $(2002,2010)$ nos advierte sobre la racionalización de la vida que podrá ocurrir a consecuencia de la absorción de la emancipación 
por la regulación en el transcurso de la convergencia entre la modernidad y el capitalismo. En este caso, la emancipación se agota en la propia regulación, volviendo la ciencia una racionalidad hegemónica con la imposición de la racionalidad instrumental sobre otras racionalidades, es lo que Santos denomina como hipercientificización de la emancipación. Así, el mercado se vuelve un principio regulador moderno que solapa al principio del Estado y el principio de la comunidad, a esto él denomina como hipermercaderización de la regulación. Este entendimiento, conduce según

[...] la necesidad de romper con las contradicciones y dicotomías que este paradigma generó en función de sus ilusiones de poder y conquistas deliberadas. Debe tomar conciencia de que el patrón de consumo instaurado en todos los ámbitos de la vida social es insostenible si perdura ese modelo de desarrollo sostenido en los pilares de la economía y de la política.

Para eso es necesario controlar los excesos, contener los deseo de poder y control, buscar establecer la armonía y la exacta medida, la sabiduría que permita a la humanidad aprender y enseñar a no olvidar los límites, a valorar lo simbólico y contener los excesos. En otros términos, soportar el deseo violento de la hybris (desmedida) y elegir como virtud la sophrosyne (prudencia, moderación, autocontrol) (SILVA, 2015, p. 17).

De esta forma, el ritmo acelerado de los grandes descubrimientos, los avances científicos y tecnológicos, señalan para un lado negativo, como la consolidación del positivismo, que, de forma exagerada, valoraba el conocimiento científico, al tiempo en que excluía otras formas de tratamiento consideradas expresiones inferiores y superadas de la experiencia humana, tales como el mito, la religión y aún la filosofía, en que el conocimiento se iguala al poder, o sea, tener conocimiento es tener poder. Por eso los modernos según Latour (1994, p. 44) “detienen todas las fuentes de poder", y este es un aspecto que Latour considera como la base de la política moderna.

Sin embargo, el ritmo acelerado señala, también, hacia un lado positivo como el desarrollo de las ciencias biológicas y de la medicina, crecimientos estos que no deben ser vistos de forma aislada, sino como una conexión de discusiones científicas que promovieron cambios cualitativos, como la teoría de la evolución de las especies, de Charles Darwin; la evolución como procesada por mutaciones, de Hugo Marie de Vries; las leyes de la herencia genética, de Gregpor Mendel; la ciencia de la bacteriología, de Louis Pasteur, convenciendo a todos que la generación espontánea no existió, contribuyendo de forma fecunda al progreso de la medicina, con el descubrimiento de que las enfermedades son producidas por gérmenes (ANDRADE, 2008).

Reconociendo los puntos positivos, se aclara que, "la crítica no se vuelca hacia la razón, sino hacia el uso de la razón como único camino hacia el conocimiento verdadero" 
(FRANCELIN, 2004, p. 29). Corroborando Santos (1995, p. 57), "no desprecia el conocimiento que produce la tecnología, pero entiende que, tal como el conocimiento se debe traducir en autoconocimiento, el desarrollo tecnológico debe traducirse en sabiduría de la vida". De esta forma, la superación de esta visión del mundo implica en

[...] conocer el sentido de este paradigma y asumir una posición revolucionaria, radical, forjar una nueva conciencia para la humanidad capaz de superar la vigencia de esta tiranización de lo real, fundada, en gran medida en los mecanismos de una explicación particularizada del mundo que desconsidera la unidad del todo y sus partes. Se trata de las explicaciones meramente deductivas que ignora el sentido de las correlaciones entre sujeto, conocimiento, mundo, mercado, Dios, naturaleza, humanidad etc. Todo eso compone la complejidad ontológica del mundo y no puede ser explicado mecánicamente, en una simple descomposición y composición del todos y sus partes como en el método cartesiano (SILVA, 2015, p. 8).

Por lo tanto, hay una necesidad de reconocerse y de buscar otras alternativas civilizatorias, como también, es necesario hacer emerger de su íntimo una decisión por la vida, implicando en la "estructuración de una nueva ética, de una nueva moralidad en la relación del hombre con la naturaleza y con el otro hombre" (SILVA, 2015, p. 12).

\section{Conceptos contemporáneos: el desafío al paradigma moderno}

La búsqueda del conocimiento y de la tecnología en la historia de la humanidad, específicamente, en la modernidad, comprendió periodos de grandes conquistas con la predominancia de la razón indolente, que proporcionó, a las sociedades, riquezas y ventajas, promesas que crearon una falsa aspiración para la población mundial y que trajeron consecuencias imprevistas a los sujetos, que quedaron marcados por el hambre, miseria, destrucción, alteraciones de valores, entre otros. Así, para superar ese modelo de paradigma sociocultural, Santos (2011, p. 20) señala la necesidad de crear un "nuevo modo de producción de conocimiento", en vez de continuar en búsqueda de un nuevo conocimiento o continuar en la forma doctrinaria de producción del conocimiento, pues la razón indolente se manifiesta con la permanencia de la rutina del conocimiento que se tiene como único... como verdadero.

Consolidada la crisis del paradigma sociocultural, surgieron diferentes movimientos y corrientes filosóficas, que se presentaron como indicativos de una nueva concepción del mundo, del ser humano, de la realidad, rompiendo distinciones y diferencias ${ }^{2}$, en un intento de

\footnotetext{
2 La ruptura de las diferencias en el sentido que las trata Santos (2010, 2011) en la Sociología de las Ausencias (ver Figura 1). "Las diferencias no existen para que sean respetadas, ignoradas o subsumidas, sino para que sirvan de atractivo a los sentimientos, de alimento para el pensamiento" (LATOUR, 2002b, p. 106).
} 
reconectar (fusión), de revalorar y reaproximar actor e interlocutores, influyendo en el contexto social, señalando posibilidades de cambios, al mismo tiempo que surgían otras racionalidades como resultado de una nueva configuración de subjetividad, es decir, la racionalidad global (razón), fragmentada en aquel momento por la emergencia de mini racionalidades que circulan en múltiples espacios ${ }^{3}$ de la sociedad y cada una "construye un sentido común específico", o sea, cada una consiste, de forma epistemológica, en una determinada unidad de práctica social, instituciones, dinámicas de desarrollo, formas de poder y de derecho (SANTOS, 2002, 2010).

Así, se espera que las concepciones contemporáneas promuevan una nueva mirada hacia el hacer ciencia, en que la ciencia no sea un vehículo de monocultivos, y para ello los investigadores tienen que asumir un cambio de postura científica. En este sentido, se presentan a continuación dos movimientos, que en nuestra perspectiva, traen a las concepciones contemporáneas una perspectiva de superación a la ausencia provocada por los monocultivos de la razón indolente.

El primer movimiento es la racionalidad ambiental, aquí se traen ejemplos teóricos de Boaventura de Sousa Santos y Félix Guattari. Santos (2010, 2011), en este caso, propone la implantación de la ecología de los saberes, pautado en cinco principios ecológicos (Figura 2).

Figura 2 - Los cinco principios ecológicos de Boaventura

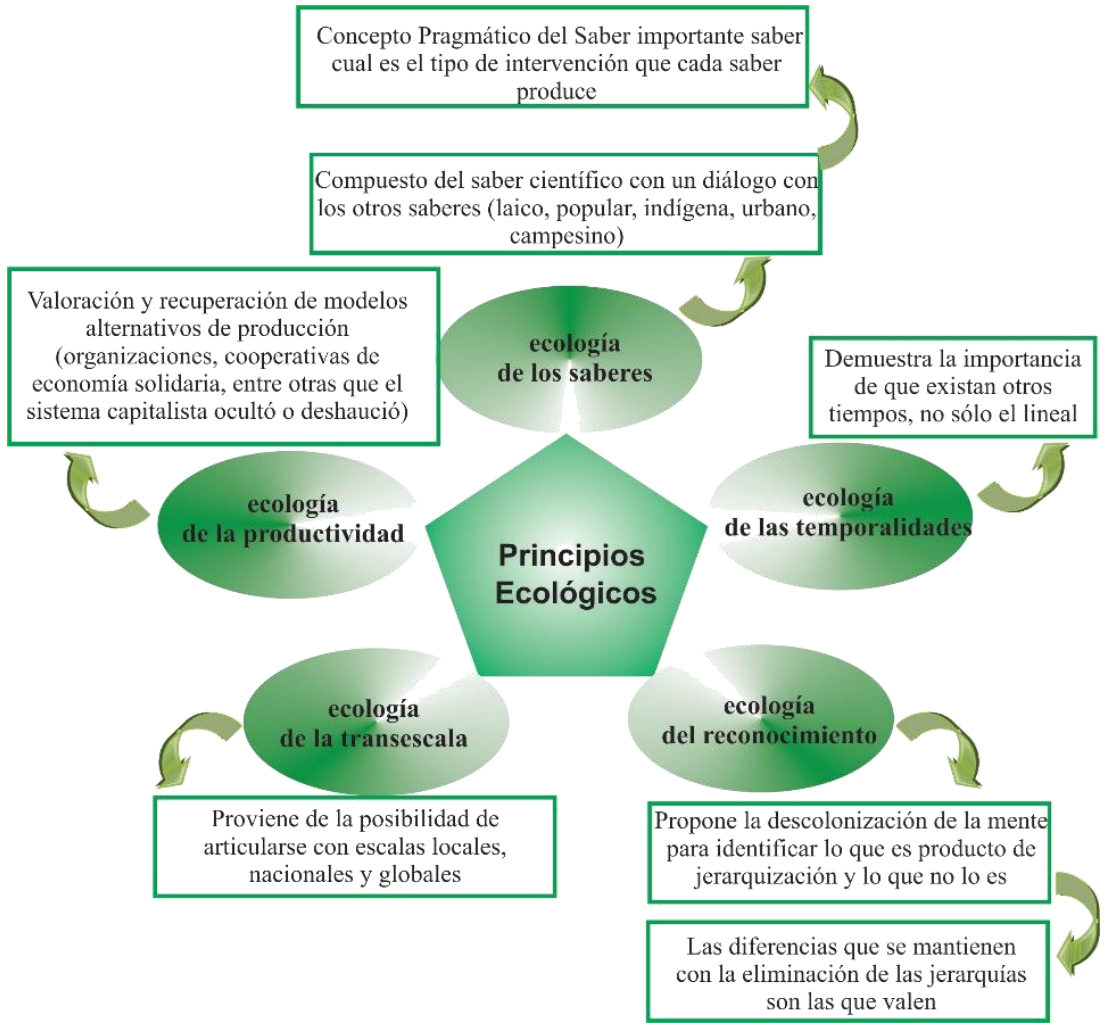

Fuente: Elaboración basada en Santos (2010, 2011)

3 Para Santos (2002), los múltiples espacios de la sociedad en que circula el sentido común son el doméstico; la producción; el mercado; la comunidad; la ciudadanía y lo mundial. 
Guattari (2001), por su parte, propone tres registros ecológicos: medioambiente, relaciones sociales y subjetividad humana, mientras que, para el autor, sólo la articulación ético política - lo que él denomina de ecosofía - entre estos tres registros podrán aclarar los interrogantes ambientales (Figura 3), pues hay una "estandarización de los comportamientos" y una "aceleración de las mutaciones técnico científicas" (GUATTARI, 2001, p. 8).

Figura 3 - Registro ecológico de Guattari

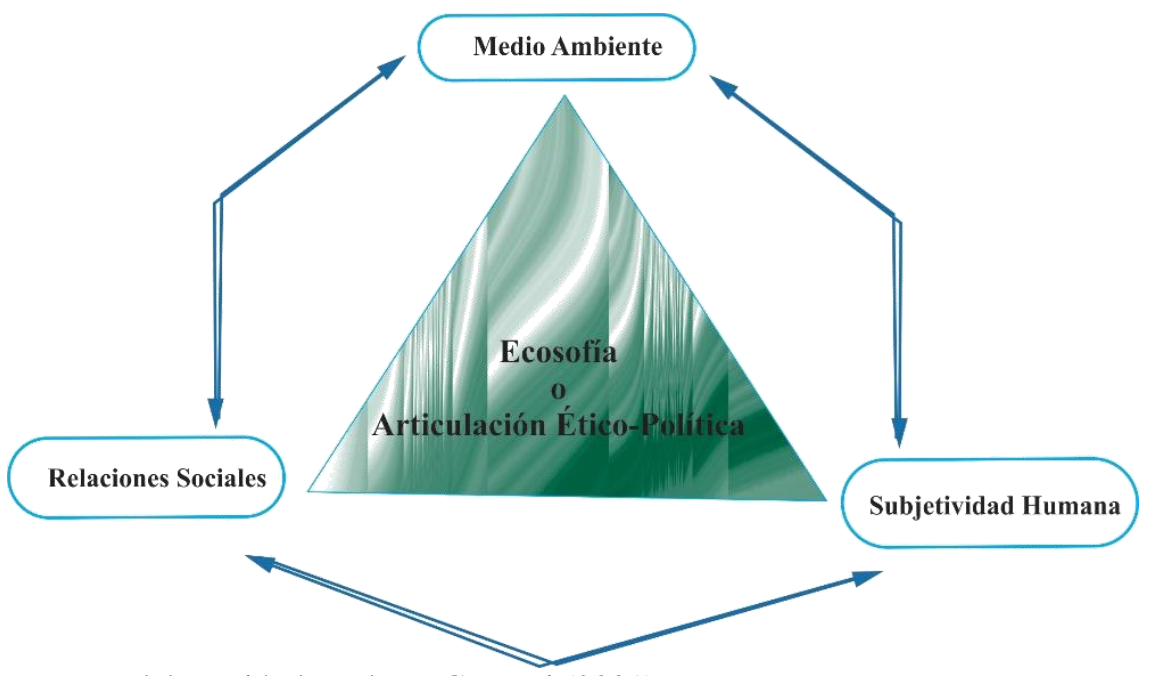

Fuente: Elaboración basada en Guattari (2001)

A través de los modelos presentados por Santos $(2010,2011)$ y Guattari (2001) se observa que hay, por parte de los autores, una preocupación en valorar otros saberes que son oprimidos y separados por el paradigma hegemónico. Estos modelos traen un diálogo entre los saberes que pueden promover la interacción/articulación en las relaciones sociales, y es en estas interacciones/articulaciones que colectivamente se realizan los procesos de producción del conocimiento. Esta concepción contemporánea señala un nuevo camino, que nos invita a caminar, y que según Santos (2014) un camino sólo se hace al caminar, lo que presupone la importancia de la participación, de la colectividad en la gestión de estos modelos.

Mediante lo expuesto, en un intento de superación del paradigma sociocultural dominante, se presentará la cartografía de controversias como el segundo movimiento contemporáneo. Este movimiento encuentra respaldo en la teoría de actor-red (ANT) de Bruno Latour.

En primer lugar, hay que destacar que para Latour (2002) en este momento de la historia de la ciencia la palabra "encantamiento" da al lenguaje un nuevo sentido, un sentido vigoroso que ya se había perdido, porque posibilita enfrentar el pavor y traer beneficios a las relaciones. De esa forma, al sujeto en la acción de enfrentarse y relacionarse lo atajan elementos siempre presentes, que muchas veces se destacan por controversias, que en la comprensión de Latour 
(2012, p. 120), su estudio "constituye uno de los primeros lugares privilegiados donde objetos pueden mantenerse por más tiempo como mediadores visibles, diseminados y reconquistados antes de convertirse en intermediarios invisibles".

Uno de estos mediadores visibles que Latour presenta, son las controversias, las cuales pueden referirse a una disputa, un debate o una polémica por un determinado objeto, pero que se caracteriza por existir dos polos (a favor o contra), donde para que se originen, será necesario que exista un foco de la disputa que puede partir del producto o del proceso y un portavoces para la construcción de "argumentos que conduzcan o aparten los artefactos para/de una condición de producidos" (NOBRE; PEDRO, 2010, p. 52). En este caso, la existencia o no de disputa en un objeto, se considera que ahí hemos constituido un mecanismo de "caja gris" y "caja negra", que en la primera la cuestión aún conlleva controversias o interrogantes y en la segunda estas cuestiones dan por concluidas (PEDRO, 2008, p. 9). En este caso, para hacer posible acompañar las controversias, se debe situar una investigación en los momentos de construcción de cajas negras (LATOUR, 2000).

Para Latour (2012, p. 53) las controversias "proporcionan al analista los recursos necesarios para rastrear las conexiones sociales". Así, por medio del rastreo de las conexiones y asociaciones establecidas en los cinco principios de la incertidumbre se constituye la cartografía de controversias, que Pedro (2008) señala como un método que presenta singularidades con las redes, tales como la complejidad, la fluidez y la heterogeneidad. En este caso, se deben observar los movimientos en la red para seguir y/o describir a los actuantes. Lo que requiere que el cartógrafo se posicione simétricamente a las polaridades establecidas, describiendo todos los argumentos movilizados, es decir, "[...] registrar, no filtrar; describir, no disciplinar" (LATOUR, 2012, p. 88), al tiempo que, al mapear las controversias, es decir, cartografiar las controversias, significa acompañar sus acciones, sus prácticas, o sea, seguir los actores como lo propone Bruno Latour (2000), podrá ser, en la investigación, una herramienta no lineal para romper el carácter técnico de la técnica.

Para Latour $(2000,2012)$ seguir los actores al cartografiar las controversias se requieren movimientos mínimos, tales como: verificar la extensión de la red; buscar una puerta de entrada; identificar los portavoces; dar acceso a los dispositivos de inscripción; y mapear las conexiones de la red observando la producción de múltiples traducciones de los actores, o sea, "mirar con más cuidado el tipo de agregados hasta ahora reunidos y los modos como ellos se conectan unos a otros" (LATOUR, 2012, p. 43). 
Así, la "multiplicidad de las traducciones puede encontrar en las controversias una oportunidad de expresión, que el método de la cartografía permitiría delinear" (PEDRO, 2008, p. 3). Sin embargo, Pedro y Nobre nos llama la atención a que

[...] comprender y mapear las controversias requiere una especial atención a los dispositivos de saber-poder que están en acción en las redes, recordando que los argumentos lanzados no son sólo técnicos, sino que están fuertemente entrelazados con las creencias, intereses y con las otras redes en que los científicos están insertados. (PEDRO; NOBRE, 2007, p. 228).

Cartografiar controversias, para Bruno Latour, es indicar al cartógrafo la necesidad de una vigilancia permanente de sus actitudes, dando siempre valor al habla de los actores, dando atención al más insignificante de los vínculos, siendo fiel a los principios relativistas ${ }^{4}$. Así, "la tarea de definir y ordenar lo social debe ser dejada a los propios actores, no al analista. Por eso es que para recuperar cierto sentido del orden, la mejor solución es rastrear conexiones entre las propias controversias, no intentar decidir cómo resolverlas” (LATOUR, 2012, p. 44).

Al cartografiar las controversias se debe priorizar el camino indicado por el actuante ${ }^{5}$, porque la dirección y el orden por el desdoblamiento de las controversias las dan ellos, por eso y necesario el rastreo de las articulaciones sin imposición de sentido o búsqueda de patrones a priori (NOBRE; PEDRO, 2010).

Así, "el enfoque de las controversias nos trae la posibilidad de rastrear las fluidas conexiones que construyen la existencia. Se trata de un trabajo de descripción, [...]”, o sea, "La descripción, a partir de los rastros dejados por los mediadores, acaba por señalar hacia un proceso de producción de la existencia", en que los "procesos deben avanzar lentamente de traducción en traducción" con el objetivo de llegar a un relato (NOBRE; PEDRO, 2010, p. 54). En este caso, Latour (2012) señala que describir no es algo simple, para él es muy difícil, pues describir una situación determinada en su estado concreto requiere mucha atención.

Ante lo que se ha expuesto, la Cartografía de Controversias defiende que el objeto de investigación social puede ser considerado, al mismo tiempo, sujeto capaz de comprender, reflexionar e interferir en nuestros análisis y ver los sujetos formadores del mundo social como individuos insertados en tradiciones históricas, construidas por los propios sujetos, por lo que son entonces partes de la historia (LATOUR, 2012).

\footnotetext{
4 Para Latour (2012, p. 46) "el relativismo es un modo de flotar sobre los datos, no de bucear en ellos".

5 Según Pedro y Nobre (2007) y Nobre y Pedro (2010) el término actuante es utilizado por Bruno Latour para designar los humanos (sujetos) y no humanos (objetos) que actúan en la red. En este caso, el actuante es aquel que puede generar redefiniciones de la realidad y tejer nuevos controles.
} 
Por lo tanto, se debe tratar de delinear una Cartografía de Controversias que tenga como finalidad permitir la aparición de argumentos diversos, que puedan dar voz a los actuantes múltiples que se solapan, o sea, se entrelazan en la red (NOBRE; PEDRO, 2010).

Según Latour (2011) tras el resultado de la gran transformación en nuestras visiones del mundo la propia noción de red introdujo una nueva historia de la ciencia, pues la transformación de la producción del objeto y de la objetividad ocurre cuando se retratan simultáneamente en el mundo y dentro de sus redes de producción.

Para Pedro (2008, p. 1) "la noción de red se ha configurado en concepto clave para la comprensión de las dinámicas sociales contemporáneas, ocupando cada vez más espacio en las investigaciones académicas, articulando diferentes campos del saber".

Según Pinto y Junqueira (2008, p. 34-35) "las redes se componen de personas, [...] La calidad e intensidad de estas conexiones son los principales factores de acoplamiento entre cada actor y la red en su conjunto, en la consecución de los objetivos individuales y los del grupo y en el ejercicio de ser poder". De este modo, los vínculos forman las conexiones o lazos que suceden entre los componentes a partir de la dinámica de la red. La orientación y la fuerza de las relaciones y de los lazos sociales son las que conectan los pares de actores y las que componen los lazos sociales (PINTO; JUNQUEIRA, 2008).

El análisis de las redes sociales posibilita la visualización de las relaciones del micro poder existente, por ejemplo, en una Institución Educación Superior (IES). Para Pinto y Junqueira (2008, p. 35) es necesario visualizar no sólo el medio en que se expresan las relaciones de poder intra reticulares, sino la construcción de un proyecto colectivo de poder.

En cuanto al poder que emana en la red, Nobre y Pedro (2010, p. 52) advierten que es importante percibir que aunque la actividad no emana, o que no hay poder, se debe llamar la atención a que "hay sí un poder difuso, esparcido por la red, a veces distribuido, otras veces cristalizado en algunos nudos". Lo que caracteriza un ordenamiento a partir de mediaciones que no es fijo, es más o menos estable, y genera movimientos que "producen, dibujan nuevos espacios".

Esto acurre, porque al trasladarse en la red, los actuantes llevan consigo su historia, lo que hace que lo transporte de su local de origen para otro local, lo que hace que la red no se convierta en un "vínculo estable y perfectamente establecido, sino antes de todo relaciones meta estables que implican en una permanente redefinición" (PEDRO, 2003, p. 33). Corroborando, Pinto y Junqueira señalan que

[...] la red es transdisciplinar, en la medida en que la producción, reproducción y difusión de conocimientos son heterogéneas, pero ampliamente accesible a 
sus integrantes. Sus fronteras tenues hacen converger una multiplicidad de habilidades y experiencias complejas. (PINTO; JUNQUEIRA, 2008, p. 35).

Acompañar las experiencias, o sea, acompañar lo que cada actor hace de la red y en la red es posible por medio de la apropiación de la traducción (PEDRO, 2008). La noción de traducción se utiliza en los estudios socio técnicos con el fin de designar cómo los actores se apropian de la red (LATOUR, 1994; PEDRO, 2003; PEDRO; NOBRE, 2007). Por lo tanto, "Traducir significa atribuir a un elemento de una red un papel a ser representado por él, una práctica que se lleva a cabo por todos los actuantes, en un movimiento mutuo y continuo, a partir de los deseos, expectativas y/o intereses de cada uno de los traductores" (PEDRO; NOBRE, 2007, p. 232).

Corroborando Bruno Latour (2011) dice que la red nos auxilia en la reformulación de cuestiones epistemológicas, filosóficas y de la vida social. Para él la red "es un hilo de Ariadna de estas historias confusas" (LATOUR, 1994, p. 9) y debe ser utilizada como un modo de investigación que es necesaria a la existencia de cualquier entidad, no para designar,

[...] un objeto exterior con la forma aproximada de puntos interconectados [...]. Ella no es nada más que un indicador de calidad de un texto [...]. El buen texto teje redes de actores cuando permite al escritor establecer una serie de relaciones definidas como otras tantas traslaciones.

[...] la red no es aquello que está representado en el texto, sino aquello que prepara el texto para sustituir los actores como mediadores.

[...] una red [...] es el trazo dejado por un agente en movimiento (LATOUR, 2012, p. 189; 192; 194).

Sin embargo, Latour (1994) nos recuerda que la red está rellena por el ser y trae una noción de puntos, del modo que estos conducen a una transformación de la forma en que la acción está ubicada o asignada y las interacciones descritas que no ocurren entre los individuos, sí en las acciones individuales distribuidas, proyectando lo que era invisible para hacerlo visible (LATOUR, 2011).

En este sentido, Latour (2002a, 2012) presenta en sus estudios, desarrollados hace veinticinco años, a partir de la teoría sociológica de Gabriel Tarde ${ }^{6}$, un nuevo abordaje aplicable en diversas finalidades, la Teoría del Actor- $\operatorname{Red}^{7} \mathrm{o}$ en francés Théorie de L'acteur-Réseau o en

6 Prof. del Collège de France, autor de incontables libros, Tarde fue la principal figura de la sociología en Francia, en el giro al siglo XX (LATOUR, 2002a). Para Latour, Tarde fue un pensador más allá de su tiempo, pues sus argumentos ya traía la noción de redes, pero no podría transformar sus intuiciones en datos, porque el mundo material en que él estaba interesado no estaba allí todavía.

7 Recordando que en el periodo del estudio la palabra "red era una novedad que podría ayudar a establecer un contraste con 'sociedad', 'institución', 'cultura', campo' etc., frecuentemente concebidas como superficies, flujos de transferencias causales y cosas concretas. Hoy, sin embargo las redes son la regla y las superficies la excepción" (LATOUR, 2012, p. 193). Así la palabra fue utilizada en el sentido de mostrar los flujos de traslaciones. La palabra red se prende por un guion a la palabra actor, donde Latour (2012, p. 193) pretende mostrar que; “a) una conexión punto por punto se establece, físicamente rastreable y, por lo tanto, lista para ser 
inglés Actor-Network Theory (ANT). La ANT proporciona al cartógrafo un medio para la producción (construcción y fabricación) de los hechos/datos de la investigación. En este método él amplía el sentido de actor, el cual pasa a ser representado tanto por humanos, como por nohumanos (artefacto), como por ejemplo las instituciones, haciendo que el actor sea definido y entendido más por lo que denomina o por su desempeño. Los actores así se comunican y se conectan en un flujo continuo, lo que pasa a caracterizarse como una red. En este aspecto, la ANT establece un diálogo con la cartografía y esta relación entre ANT/cartografía auxiliará el cartógrafo a pensar los delineamientos propuestos en la investigación, o sea, en la tarea de trazar los cambios sutiles en la conexión, de descubrir/rastrear asociaciones.

Por asociaciones, Latour (2012) establece a partir de la ANT que el enfoque de la "sociología de lo social" empleada en la ciencia de lo social en verdad sería una "sociología de las asociaciones", pues él entiende que los vínculos pueden ser también establecidos por relaciones de naturaleza no social, así, las asociaciones, posibilitan rastrear conexiones, que en sí mismas, no son sociales, por otro lado el autor expresa el deseo de redefinir "la noción de social, volviendo a su sentido original y haciéndolo de nuevo capaz de delinear las conexiones" (LATOUR, 2006, p. 1).

Las asociaciones posibilitan el mapeo del actor/red, en que sus movimientos se producen en diferentes velocidades y aceleraciones, razón por la cual, en cada instante pueden cambiar los conceptos de aquello que estaba asociado, haciendo irrelevante la definición anterior (LATOUR, 2000, 2006, 2012). En este sentido, la ANT hace una invitación a aprender a ir más despacio e ir siguiendo a cada paso las asociaciones.

Las asociaciones se presentan en un proceso dinámico de conexiones y/o desconexiones. En este sentido la ANT establece un vínculo con la cartografía de las controversias, cuando se presenta como una sociología de las asociaciones que reflexiona una narrativa, una descripción de las acciones sociales. Haciendo consideraciones sobre lo social Latour expone la siguiente lógica:

Si lo social es un bosquejo, entonces puede ser re-delineado; si es una reunión, entonces puede ser reunido [...]. Un buen relato de la ANT es una narrativa, una descripción o una proposición en la cual todos los actores hacen algo y no se quedan sólo observando. En vez de simplemente transportar efectos sin transformarlos, cada uno de los puntos en el texto puede hacer una encrucijada, un evento o el origen de una nueva traslación (LATOUR, 2012, p. 189-189).

registrada empíricamente; b) esa conexión deja vacía buena parte de aquello que no está conectado [...]. El vacío es la clave para recorrer los raros conductos por donde lo social circula". Por su parte la palabra actor "en la expresión con guion 'actor-red', no es la fuente de un acto, sí el blanco móvil de un amplio conjunto de entidades que enjambran en su dirección. [...] él representa la principal fuente de incertidumbre respecto al origen de la acción" (LATOUR, 2012, p. 75-76). 
En este caso, para la ANT no hay una realidad, sí varias realidades, volviéndose no plurales, sino múltiples. Así, la Teoría del Actor-Red "postula que el conocimiento es un producto de esta red de materiales heterogéneos, un proceso de 'ingeniería heterogénea' del cual participan lo social, lo técnico, lo conceptual y lo textual” (PEDRO, 2008, p. 5).

\section{Tejiendo las consideraciones finales}

Revisitando el movimiento del conocimiento, sus orígenes, su construcción en la/por la historia, se percibe por medio de este estudio la necesidad de hacer nuevas búsquedas teóricometodológicas que hagan posible pensar el "hacer ciencia" de manera que conduzcan a nuevos caminos que se distancien de la racionalidad instrumental.

El visitar los caminos del conocimiento hasta llegar a la racionalidad ambiental y la cartografía, nos trae la necesidad de volver a revisarlos y/o desarrollar reflexiones sobre cómo debemos desarrollar nuestras investigaciones, es decir, cómo "hacer ciencia" en la contemporaneidad de manera no-lineal. De ahí surgió la necesidad de promover la aproximación del discurso de la racionalidad ambiental al discurso de la cartografía, con el fin de que este movimiento pueda contribuir a la superación ${ }^{8}$ de la racionalidad instrumental. Es importante resaltar que la aproximación (el deslizamiento) entre estos dos movimientos sólo se hizo posible gracias a la "nueva historia de las ciencias", a esta nueva forma de pensar la ciencia (LATOUR, 2002b, p. 73; 85).

Por último, en esta crisis del modelo civilizatorio en que vivimos, la perspectiva de la racionalidad ambiental y de la cartografía, así como de la Teoría del Actor-Red, a la luz de los autores destacados en este texto, son enfoques teóricos que pueden contribuir para una postura crítica, creativa y responsable de "hacer ciencia", pudiendo llegar, éstos a ser comprendidos y adoptados como fundamentos teórico-metodológicos de la investigación científica.

\section{REFERENCIAS}

AGAMBEN, Giorgio. O que é o contemporâneo? E outros ensaios. Traducción Vinícius Nicastro Honesko. Chapecó, SC: Argos, 2009.

ANDRADE, Palloma R. de. Bem-estar psicológico de servidores e funcionários técnicoadministrativo de instituições de ensino superior pública e privada: indicadores e

\footnotetext{
${ }^{8}$ Según Latour (2002, p. 69-70), el término "superación" se "forjó durante siglos, para alimentar la polémica antifetichista de la que buscamos justamente desprendernos. [...] ahora es necesario volverse hacia los avatares del sujeto". Así en la "nueva historia de las ciencias" estos avatares creados por la racionalidad moderna, se abren hacia nuevas perspectivas. Aquí se utiliza este término en este contexto.
} 
antecedentes. 2008. 275p. Tesis (Doctorado en Psicología Social) - UFRN, Natal.

BHABHA, Homi. K. O local da cultura. Traducción Myriam Ávila, Eliana Lourenço de Lima Reis, Gláucia Renate Gonçalves. 2. ed. Belo Horizonte: Ed. UFMG, 2013.

COSTA, Evandro da F. Modernidade tecnocientífica e (in)experiência do pensamento: um espectro que ronda e desafia o processo formativo no IFPE - campus Vitória. In:

ENCONTRO DE FILOSOFIA DA EDUCAÇÃO DO NORTE E NORDESTE, 7., 2015. Anais [...]. Vitória da Conquista: PPGED/UESB, 2015. p. 155-172.

FRANCELIN, Marivalde M. Ciência, senso comum e revoluções científicas: ressonâncias e paradoxos. Ci. Inf., Brasília, v. 33, n. 3, p. 26-34, sept./dic. 2004.

GRÜN, Mauro. Ética e educação ambiental. 9. ed. Campinas: Papiro, 2005. (Colección Magisterio: Formación y trabajo pedagógico).

GUATTARI, Félix. As três ecologias. Traducción Maria Cristina F. Bittencourt. 11. ed. Campinas: Papirus, 2001.

LATOUR, Bruno. Jamais fomos modernos: ensaio de antropologia simétrica. Traducción Carlos Irineu da Costa. Rio de Janeiro: Ed. 34, 1994. (Colección Trans).

LATOUR, Bruno. Ciência em ação: como seguir cientistas e engenheiros mundo afora. Traducción Ivone C. Benedetti. São Paulo: UNESP, 2000.

LATOUR, Bruno. Gabriel Tarde and the end of the social. In: JOYCE, Patrick (Ed.). The social in question: new bearings in history and the social sciences. London: Routledge, 2002a, p. 117-132.

LATOUR, Bruno. Reflexão sobre o culto moderno dos deuses fe(i)tiches. Traducción Sandra Moreira. Bauru, SP: Edusc, 2002b.

LATOUR, Bruno. Como prosseguir a tarefa de delinear associações? Configuraciones, n. 2, p. 11-27, 2006.

LATOUR, Bruno. Networks, Societies, Spheres: Reflections of an Actor-network Theorist. International Journal of Communication, Manue Castells (ed.), v. 5, special issue, p. 796$810,2011$.

LATOUR, Bruno. Reagregando o social: uma introdução à teoria do ator-rede. Traducción Gilson César Cardoso de Sousa. Salvador: Edufba; Bauru Edusc., 2012. 399p.

LEFF, Enrique. Complexidade, racionalidade ambiental e diálogo de saberes. Educação e Realidade, v. 34, n. 3, p. 17-24, sept./dic. 2009.

MATOS, Olgária. Modernidade: o deslimite da razão e o esgotamento ético. In: NOVAES, Adauto (org.). Mutações: a experiência do pensamento. São Paulo: SESC SP, 2010. p. 157176. 
MORIN, Edgar. Os sete saberes necessários à educação do futuro. Traducción Catarina Eleonora F. da Silva e Jeanna Sawaya. Revisão Edgard de Assis Carvalho. 9. ed. São Paulo: Cortez; Brasília, DF: UNESCO, 2004.

MORIN, Edgar. Ciencia com consciencia. Traducción Maria D. Alexandre e Maria Alice Sampaio Dória. 82. ed. revisada y modificada por el Autor. Rio de Janeiro: Bertrand Brasil, 2005 .

NOBRE, Júlio C. de A.; PEDRO, Rosa M. L. R. Reflexões sobre possibilidades metodológicas da Teoria Ator-Rede. Cadernos UniFOA, n. 14, p 47-56, dic. 2010.

PEDRO, Rosa M. L. R. A redes na atualidade: refletindo sobre a produção do conhecimento. In: D'AVILA NETO, M. I.; PEDRO, R. M. L. R. (org.). Tecendo o desenvolvimento: saberes, gênero, ecologia social. Rio de Janeiro: Bapera, 2003. (Colección Estudios Interdisciplinares de Comunidades y Ecología Social - EICOS).

PEDRO, Rosa M. L. R. Redes e Controvérsias: ferramentas para uma cartografia da dinamica psicossocial. In: ESOCITE - JORNADAS LATINO-AMERICANAS DE ESTUDOS SOCIAIS DAS CIENCIAS E DAS TECNOLOGIAS, 7., 2008, Anais [...]. Rio de Janeiro: UNIRIO, 2008. Disponible en: http://www.necso.ufrj.br/esocite2008/resumos/36356.htm. Acceso el: 19 ago. 2015.

PEDRO, Rosa M. L. R.; NOBRE, Júlio C. de A. Redes de bioética e biotecnologias da reprodução: controvérsias teóricas e metodológicas. RECIIS - R. Eletr. de Com. Inf. Inov. Saúde, Rio de Janeiro, v. 1, n. 2, p. 224-233, jul./dic., 2007. Doi: 10.3395/reciis.v1i2.87pt

PIMENTEL, Edna F. Aspectos teórico-metodológicos da filosofia da educação. In: ENCONTRO DE FILOSOFIA DA EDUCAÇÃO DO NORTE E NORDESTE, 7., 2015. Anais [...] Vitória da Conquista: PPGED/UESB, 2015. p. 104-119.

PINTO, Áureo M. G.; JUNQUEIRA, Luciano A. P. A análise de redes sociais como ferramenta de diagnóstico das relações de poder. e Gesta - Revista Electrónica de Gestión de Negocios, v. 4, n. 1, ener./mar. 2008, p. 33-59.

SANTOS, Boaventura de S. Um discurso sobre as ciencias. 7. ed. Porto, Portugal: Afrontamento, 1995. (Colección Historia e Ideas).

SANTOS, Boaventura de S. A crítica da razão indolente: contra o desperdício da experiencia (Para um novo senso comum: a ciencia, o direito e a política na transição paradigmática). 4. ed. São Paulo: Cortez, 2002. v. 1.

SANTOS, Boaventura de S. Pela mão de Alice: o social e o político na pós-modernidade. 12. ed. São Paulo: Cortez, 2008.

SANTOS, Boaventura de S. A gramática do tempo: para uma nova cultura política (Para um novo senso comum: a ciência, o direito e a política na transição paradigmática). 3. ed. São Paulo: Cortez, 2010. v. 4.

SANTOS, Boaventura de S. Renovar a teoria crítica e reinventar a emancipação social.

Traducción Mouzar Benedito. 1. ed. revisada. São Paulo: Bomtempo, 2011. 
SANTOS, Boaventura de S. A Práxis da Ecologia de Saberes: entrevista com Boaventura de Sousa Santos. Entrevista concedida a Fernando Ferreira Carneiro, Noemi Margarida Krefta, Cleber Adriano Rodrigues Folgado. Tempus, Actas de Salud Colet, Brasilia, v. 8, n. 2, p. 331-338, jun. 2014.

SILVA, Adelson F. da. A tirania da autoridade antropocentrica do homem moderno sobre o mundo natural. In: ENCONTRO DE FILOSOFIA DA EDUCACIÓN DO NORTE E NORDESTE, 7., 2015. Anais [...] Vitória da Conquista: PPGED/UESB, 2015. p. 1-18.

\section{SOBRE OS AUTORES:}

\section{Celeste Días Amorim}

Doctora en Desarrollo y Medioambiente por la Red Prodema, UESC. Maestro en Ciencias Ambientales, UESB; Profesora Faculdade Pitágoras; Pertenece al Grupo de Investigaciones sobre la Circulación de Ideas Pedagógicas en el Pensamiento Pedagógico Brasileño Reciente (CIPED/UESB). E-mail: celamorim@gmail.com

(iD https://orcid.org/0000-0001-9656-3470

\section{Luis Artur de Santos Cestari}

Doctor en Educación por la UFPE, Docente del Programa de Ciencias Ambientales, UESB. Grupo de Investigaciones sobre la Circulación de Ideas Pedagógicas en el Pensamiento Pedagógico Brasileño Reciente (CIPED/UESB). Profesor Titular de la UESB. Actua en dos programas de post-grado: PPGEd/UESB y el PPGCA/UESB. E-mail: lacestari@ hotmail.com (iD) https://orcid.org/0000-0002-1842-2207 